\title{
Growth inhibition properties of the putative prostate cancer biomarkers PSP94 and CRISP-3
}

\author{
Aleyde Van Eynde, Kirill Litovkin and Mathieu Bollen \\ Asian Journal of Andrology (2011) 13, 205-206; doi:10.1038/aja.2010.120; published online 22 November 2010 \\ This article has been corrected since Advance Online Publication and a corrigendum is also printed in this issue.
}

One of the major problems in prostate cancer (PCa) diagnosis and treatment relates to the difficulty in discriminating between slowgrowing, indolent cancers and more aggressive tumors with a lethal outcome. ${ }^{1}$ Therefore, much research has been devoted to the identification of reliable biomarkers that predict disease progression and treatment outcome. Two interacting prostate proteins, namely, the prostatic secretory protein of 94 amino acids (PSP94), encoded by the MSMB gene, and the cysteine-rich secretory protein CRISP-3, also known as SGP28, have been advanced as PCa biomarkers. ${ }^{2-5}$ In parallel, much attention has gone to the functional characterization of these proteins. Pathak et l. $^{6}$ now report in the Asian Journal of Andrology that both PSP94 and CRISP-3 function as growth inhibitors of subsets of PCa cell lines, despite their inversely correlated expression levels during $\mathrm{PCa}$ progression (Figure 1a). Intriguingly, the CRISP-3-mediated growth inhibition was not affected by the presence of PSP94, suggesting a PSP94-independent role for CRISP-3 in prostate tumorigenesis.

PSP94 (10.7 kDa), also known as $\beta$-microseminoprotein or inhibin, is a small cysteinerich protein, whereas CRISP-3 $(28 \mathrm{kDa})$ is a glycoprotein with an amino-terminal sperm coating glycoprotein domain and a carboxyterminal cysteine-rich domain. Both PSP94 and CRISP-3 are synthesized by the epithelial cells in the prostate gland and are secreted into the seminal plasma. ${ }^{2,7}$ In the seminal fluid of healthy males PSP94 is much more abundant than CRISP-3. However, both pro-

Laboratory of Biosignaling and Therapeutics, Department of Molecular Cell Biology, Faculty of Medicine, KULeuven, Leuven B-3000, Belgium Correspondence: Dr A Van Eynde (Aleyde.VanEynde@ med.kuleuven.be) teins can also be detected in serum where the level of PSP94 correlates with that in seminal plasma. ${ }^{8}$ However, this correlation does not hold for CRISP-3, because the latter is also derived from other sources, including neutrophilic granulocytes. Several gene expression-profiling and immunohistochemical studies have revealed that the expression of the MSMB gene gradually decreases during development PCa, i.e., from primary PCa to the late, highly invasive, androgen-independent state (reviewed in Ref. 2). In contrast, CRISP-3 is among the most upregulated genes in $\mathrm{PCa}^{5,7}$ (Figure 1a). Importantly, the altered levels of CRISP-3 and PSP94 in PCa are associated with a poor outcome in patients that underwent radical prostatect-

a

Normal
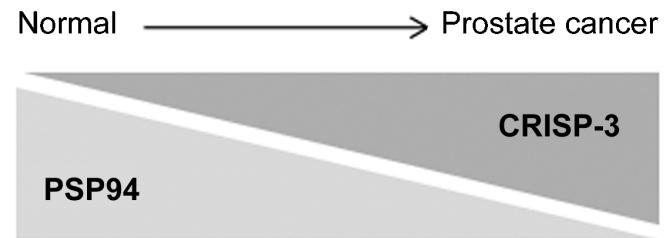

b

Homo-dimers

omy, suggesting that these proteins have potential as predictive biomarkers for $\mathrm{PCa}{ }^{9}$

The MSMB gene is (epi)genetically silenced in PCa. ${ }^{10-13}$ Recently, genome-wide association studies identified a C/T single nucleotide polymorphism rs10993994 in the promoter region of the $M S M B$ gene that correlated with a significantly increased risk of developing PCa. ${ }^{10,11}$ The 'TT' genotype, comprising two risk alleles, was associated with a lower expression of the MSMB gene and a severely decreased binding of the transcription factor CREB (cyclic AMP response element-binding protein), which was explained by changes of the CREB-binding site. ${ }^{12}$ In addition, the expression of MSMB is downregulated in PCa by methylation of 
CpG islands as well as by Polycomb-regulated histone modifications, which are both known to silence genes by making them less accessible to transcription factors. ${ }^{13}$ It is not yet known whether the CRISP-3 gene is also (epi)genetically misregulated in PCa.

PSP94 is a multifunctional protein; it modulates circulating follicle-stimulating hormone levels, regulates sperm function and inhibits tumor growth. ${ }^{2}$ It also reduces the proliferation of rat cancer cell lines, human androgen-independent prostate cell lines and xenografted tumors by inducing apoptosis. ${ }^{14,15}$ The current view is that the biological effects of PSP94 are largely mediated by protein-protein interactions. Indeed, PSP94 attaches to cell membranes and forms homo- and heterodimers (Figure 1b). Its heterodimeric partners comprise a variety of proteins, including CRISP-3, CRISP-9 (also known a PSP94-binding protein), immunoglobulines and cell surface receptors like the laminin receptor 37LRP. ${ }^{2,16}$ The binding of PSP94 to cell surface receptors inhibits the secretion of the metalloproteinase MMP9 and signaling by the angiogenic factor VEGF (vascular endothelial growth factor), which at least partially accounts for its antimetastatic effect. ${ }^{17}$ The biological function of CRISP-3 is linked to innate immunity and inflammation, consistent with its expression in neutrophilic granulocytes, but its role in PCa is not understood. ${ }^{7}$ In seminal fluid, PSP94 is much more abundant than CRISP3 , suggesting that the entire pool of CRISP-3 is likely to be complexed with PSP94. ${ }^{18}$ In human blood, however, CRISP-3 is known to bind to the human plasma protein AIBG, ${ }^{19}$ whereas PSP94 is complexed to CRISP-9. ${ }^{20}$ It seems likely that the increased CRISP-3 and decreased PSP94 levels in PCa have considerable effects on the ratio of the distinct PSP94 complexes.

Pathak and colleagues ${ }^{6}$ now report that both PSP94 and CRISP-3 inhibit the growth of PCa cells and they do so in a cell linespecific manner. Growth inhibition by PSP94 is not a novel finding, but it comes as a surprise that CRISP-3 acts as a growth inhibitor, given its upregulation in $\mathrm{PCa}^{9}$ The ectopic expression of PSP94 was assoc- iated with a decreased colony formation of the PCa cell lines LNCaP and WPE1-NB26, but not of the prostate carcinoma PC-3 cell line. The absence of an effect on PC- 3 cells is at variance with another report ${ }^{14}$ and the generally established function of PSP94 as a tumor suppressor. However, as suggested by the authors, such differences can be due to the distinct modes of PSP94 delivery, i.e., by the transfection of the PSP94-expressing construct $^{6}$ or the addition of PSP94 protein to the culture medium. ${ }^{14}$ The ectopic expression of CRISP-3 caused a growth inhibition of PC-3 and WPE1-NB26 cells, but not of LNCaP cells, which represents a cell line specificity that is different from that of PSP94. Moreover, growth inhibition of PC- 3 cells by CRISP-3 was not affected by the stable expression of PSP94, which is further evidence that this effect of CRISP-3 is not mediated by PSP94. A limitation of the study of Pathak et al. ${ }^{6}$ is that the growth inhibition assays were based on the assumption that the transfection efficiency and the antibiotic selection are identical for the empty and PSP94-/CRISP-3-expressing plasmids, which is not trivial. This limitation could be overcome by using stable cell lines, preferentially with an inducible system. The use of stable inducible cell lines would also make it possible to compare the effects of PSP94 on CRISP-3-negative and -positive cells.

1 Getzenberg RH. Novel approaches for the molecular classification of prostate cancer. Asian J Androl 2010; 12: 620-2.

2 Whitaker HC, Warren AY, Eeles R, Kote-Jrai Z, Neal $D E$. The potential value of microseminoprotein- $\beta$ as a prostate cancer biomarker and therapeutic target. Prostate 2010; 70: 333-340.

3 Nam RK, Reeves JR, Toi A, Dulude H, Trachtenberg J et al. A novel serum marker, total prostate secretory protein of 94 amino acids, improves prostate cancer detection and helps identify high grade cancers at diagnosis. J Urol 2006; 175: 1291-7.

4 Kosari F, Asmann YW, Cheville JC, Vasmatzis G. Cysteine-rich secretory protein-3: a potential biomarker for prostate cancer. Cancer Epidemiol Biomarkers Prev 2002; 11: 1419-26.

5 Bjartell AS, Johansson R, Björk T, Gadaleanu V, Lundwall $A$ et al. Immunohistochemical detection of cysteine-rich secretory protein 3 in tissue and in serum from men with cancer or benign enlargement of the prostate gland. Prostate 2006; 66: 591-603

6 Pathak BP, Breed AA, Nakhawa VH, Japtap DD, Mahale SD. Growth inhibition mediated by PSP94 or CRISP-3 is prostate cancer cell line specific. Asian J Androl 2010; 12: 677-89.

7 Gibbs GM, Roelants K, O'Bryan MK. The CAP superfamily: cysteine-rich secretory proteins, antigen 5, and pathogenesisrelated 1 proteinsroles in reproduction, cancer, and immune defense. Endocr Rev 2008; 29: 865-97.

8 Valtonen-André C, Sävblom C, Fernlund P, Lilja H, Giwercman A et al. Beta-Microseminoprotein in serum correlates with the levels in seminal plasma of young, healthy males. J Androl 2008; 29: 330-337.

9 Bjartell AS, Al-Ahmadie H, Serio AM, Eastham JA, Eggener SE et al. Association of cysteine-rich secretory protein 3 and beta-microseminoprotein with outcome after radical prostatectomy. Clin Cancer Res 2007; 13: 4130-8.

10 Eeles RA, Kote-Jarai Z, Giles GG, Olama AA, Guy M et al. Multiple newly identified loci associated with prostate cancer susceptibility. Nat Genet 2008; 40: 316-21.

11 Thomas G, Jacobs KB, Yeager M, Kraft P, Wacholder S et al. Multiple loci identified in a genome-wide association study of prostate cancer. Nat Genet 2008; 40: 310-5

12 Lou H, Yeager M, Li H, Bosquet JG, Hayes RB et al. Fine mapping and functional analysis of a common variant in MSMB on chromosome 10q11.2 associated with prostate cancer susceptibility. Proc Natl Acad Sci USA 2009; 106: 7933-8.

13 Beke L, Nuytten M, van Eynde A, Beullens M, Bollen $M$. The gene encoding the prostatic tumor suppressor PSP94 is a target for repression by the Polycomb group protein EZH2. Oncogene 2007; 26: 4590-5.

14 Garde SV, Basrur VS, Li L, Finkelman MA, Krishan A et al. Prostate secretory protein (PSP94) suppresses the growth of androgen-independent prostate cancer cell line (PC3) and xenografts by inducing apoptosis. Prostate 1999; 38: 118-25.

15 Shukeir N, Arakelian A, Kadhim S, Garde S, Rabbani SA. Prostate secretory protein PSP94 decreases tumor growth and hypercalcemia of malignancy in a syngenic in vivo model of prostate cancer. Cancer Res 2003; 63: 2072-8

16 Kumar A, Jagtap DD, Mahale SD, Kumar M. Crystal structure of prostate secretory protein PSP94 shows an edge-to-edge association of two monomers to form a homodimer. J Mol Biol 2010; 397: 947-56.

17 Lamy S, Ruiz MT, Wisniewski J, Garde S, Rabbani SA et al. A prostate secretory protein 94-dereived synthetic peptide PCK3145 inhibits VEGF signaling in endothelial cells: implication in tumor angiogenesis. Int J Cancer 2006; 118: 2350-8

18 Udby L, Lundwall A, Johnsen $A H$, Fernlund $P$, Valtonen-André $C$ et al. beta-Microseminoprotein binds CRISP-3 in human seminal plasma. Biochem Biophys Res Commun 2005; 333: 555-61.

19 Udby L, Sørensen OE, Pass J, Johnsen AH, Behrendt N et al. Cysteine-rich secretory protein 3 is a ligand of alpha1B-glycoprotein inhuman plasma. Biochemistry 2004; 43: 12877-86.

20 Reeves JR, Xuan JW, Arfanis K, Morin C, Garde SV et al. Identification, purification and characterization of a novel human blood protein with binding affinity for prostate secretory protein of 94 amino acids. Biochem J 2005; 385(Pt 1): 105-14. 